Case Study

\title{
Trends in performance factors of wind energy facilities
}

\author{
Alberto Boretti ${ }^{1}$ iD $\cdot$ Stefania Castelletto ${ }^{2}$
}

Received: 12 March 2020 / Accepted: 16 September 2020 / Published online: 23 September 2020

(c) Springer Nature Switzerland AG 2020

\begin{abstract}
This communication discusses the two parameters recently emerged as key performance indicators of wind energy facilities, the mean capacity factor over a year, and the standard deviation of the capacity factor from a high-frequency sampling of $1 \mathrm{~min}$ or less (the annual mean does not change if the sampling interval of the statistical population is every month or every minute; the standard deviation does). Both parameters impact the levelised cost of electricity. They permit to quantify the energy production by the specific facility. They also permit to attribute grid energy storage costs to the specific facility. This manuscript shows that the annual mean capacity factors of wind energy facilities are not improving in the U.S. with the year of completion. The average of the annual mean capacity factors of every facility operational in a given year is about $33 \%$ now in 2019 as it was in 2012. Additional to the flat trend in the average of the annual mean capacity factor, their variability is large at the individual facility level. With $5 \mathrm{~min}$ sampling frequency, the standard deviation of the capacity factor of an individual wind energy facility is about that same magnitude of the mean. This translates into a coefficient of variability - the ratio of the standard deviation to the mean-approaching unity. At the grid level, the variability of all the wind energy supply is still large and necessitates significant energy storage.
\end{abstract}

Keywords Wind energy · Capacity factors · Trend analysis · Variability index

\section{Introduction}

Wind energy is presently the most widespread and economic renewable energy. The wind energy facilities use the variable wind energy resource to generate electricity $[1,2]$. Wind electricity supply is less variable than solar photovoltaics, but it still suffers from significant variability, because of the fluctuation of the wind energy resource $[3,4]$.

Junginger et al. [5] notes as the onshore wind has been characterized by reductions in the cost of installation per unit capacity for more than three decades. The reduction of the levelised cost of electricity (LCOE) is the parameter being used in this century to better assess the cost of electricity. [6] notes as turbine rotor sizes have grown from the early 1980s and with them the rated output (capacity). While different designs were considered in the past, the industry is now settled on three-blade rotors that run upwind of the tower. The larger is the rotor, the more difficult it is the packaging in arrays on limited land. By increasing the rotor diameter, also the tower height increases, and this permits to harvest larger wind energy as the wind speed increases with height. Presently, the registered capacity of wind energy installations is simply the arithmetic sum of the rated power of every turbine, no matter how they are installed on a given terrain, which are the prevailing wind and other atmospheric conditions, or which is the height of the rotor.

The annual mean capacity factor is a critical operating performance parameter and has an economic value as it enters in the LCOE. Methods to predict the capacity factors based on a statistical model of wind resources

$\triangle$ Alberto Boretti, a.a.boretti@gmail.com; Stefania Castelletto, stefania.castelletto@rmit.edu.au | ${ }^{1}$ Mechanical Engineering Department, College of Engineering, Prince Mohammad Bin Fahd University, Al Khobar, Saudi Arabia. ${ }^{2}$ School of Engineering, RMIT University, Bundoora, Australia. 
and wind turbine power output have been developed in recent years, just to cite few recent works [7-10]. However, capacity factors calculated with the above methods provide only insight on the resource potentials and a very approximated techno-economic outlook, as they do not often reflect real production values of capacity factors also affected by terrain effects, wake effects, power output dependence on temperature and pressure at the turbine, and maintenance periods.

Very few papers in the literature are showing actual capacity factors and their inter- and intra-year variability. A study on an entire fleet of U.K. onshore wind farms is reported in [11], where the capacity factors are determined monthly from published actual performance-based information, showing the degradation of $1.6 \%$ of energy production on average per year, with an increase of $\angle C O E$ of $9 \%$ over 20 years. An extension of this work to off-shore wind farms has been recently published [12]. A detailed work based on observed energy production data in the U.S. from 1990 to 2016 provides the wind and solar the rate of energy generation per unit of land surface area, from primary data, primary plant-level data, and prior datasets on capacity density $[13,14]$. This work shows that wind power observed capacity factors are increasing, but that increase is associated with a decrease in capacity densities, so power densities are stable or declining. Recently case study on individual wind farms proposed the comparison between real and modeled capacity factors [15].

In the U.S. [16] reports the CapEx (capital expenditure per unit installed power) plus the weighted average annual mean capacity factors of different techno-resource group (TRG) areas [17-19]. The LCOE is then computed based on CapEx, annual mean capacity factor, operation and maintenance costs $(O \& M)$, a loss of performance with aging factor, and financial parameters. These areas are characterized by different mean wind speed and wind speed range. The variability of the capacity factors is not considered.

Within the United States, in 2017, wind turbines contributed $6.3 \%$ of the total utility-scale electricity generation, with a growth from 2000 to 2017 from 6 to 254 billion kWh. Over the last few years, wind energy electricity production has increased less than the wind energy capacity (installed power).

On-shore based wind energy facilities in the United States are discussed in [20-24]. These wind plants have a capacity in the range from 50 to $100 \mathrm{MW}$ [21], with an average 2-MW turbine with a rotor diameter of $102 \mathrm{~m}$ and hub heights of $82 \mathrm{~m}$. These works are mostly based on the facilities up to 2015 [22]. A renewable energy technical potential is defined in [23] as the achievable energy generation per specific turbine installation. The technical potential is quantified by capacity factors. The capacity factors estimated are based on five different wind turbines, optimized for the range of annual wind speed at the locations. The chosen wind turbine power curves were representative of the facilities of 2015 [22].

Most installed U.S. wind plants align with ATB estimates for performance in TRGs 5-7. TRGs 1-2 are high wind resource sites. TRGs $8-10$ are exceptionally low wind resource sites. Wind energy facilities in TRGs 8-10 are uncommon. For a TRG 1 of wind speed range $8.2-13.5 \mathrm{~m} / \mathrm{s}$, and mean $8.7 \mathrm{~m} / \mathrm{s}$, it is expected a $47.4 \%$ annual mean capacity factor [21]. For a TRG10, with a wind speed range of $1.0-5.3 \mathrm{~m} / \mathrm{s}$, and mean $4.0 \mathrm{~m} / \mathrm{s}$, it is expected an $11.1 \%$ annual mean capacity factor [21]. In the most common conditions of TRGs $5-7$, where the wind speed range is $6.9-11.1$ to $5.4-8.3 \mathrm{~m} / \mathrm{s}$, and the mean speed is $7.5-6.2 \mathrm{~m} / \mathrm{s}$, the expected annual mean capacity factor is $40.7-30.8 \%$ [21]. Seasonal variability is only discussed in [25] for typical areas of the U.S., showing everything but dramatic changes over 1 year. These are the supposed to be evidence-based performances of wind turbines in onshore installations within the US.

The future projections presented in the ATB [16] are based on high, medium, and low-cost estimates. They are the results of a survey of 163 of the world's wind energy experts [23]. It is generally accepted that the annual mean capacity factors of land-based wind energy facilities in the U.S. have been increasing in recent years [16], and are further dramatically increasing at present, see Fig. $1 \mathrm{a}$. It is similarly shown that the CapEx (capital cost per unit installed power) has been dramatically reducing since 2010, and it is further dramatically reducing now. Here we do not consider the CapEx aspect, as reliable information about costs is not available. Here we consider the capacity factor, the annual mean value, and a variability parameter, from reliable data of electricity production.

The capacity factor is the ratio of the mean generating power over a year to the nominal power. If $E_{a}$ is the electricity produced in 1 year, $P$ is the nominal power of the wind energy facilities, simplistically takes as the sum of the nominal power of the different turbines, the annual mean capacity factor is $\varepsilon_{a \text {. }}$

$\varepsilon_{a}=\frac{E_{a}}{P \cdot n_{a}}$

where $n_{a}$ is the number of hours in 1 year. In this equation, $E_{a}$ is in $\mathrm{MWh}$ and $P$ in MW. According to Fig. 1, the average value of the different facilities is $33 \%$ in 2011, and it has been grown steadily to $43 \%$ of 2016 . The figure shows a range of capacity factors based on variation in the resource. Theoretically, the historical data are from wind plants operating in the U.S. in 2015, according to the year in which the plants were completed. The range of estimates illustrates the effect of sites with high wind 

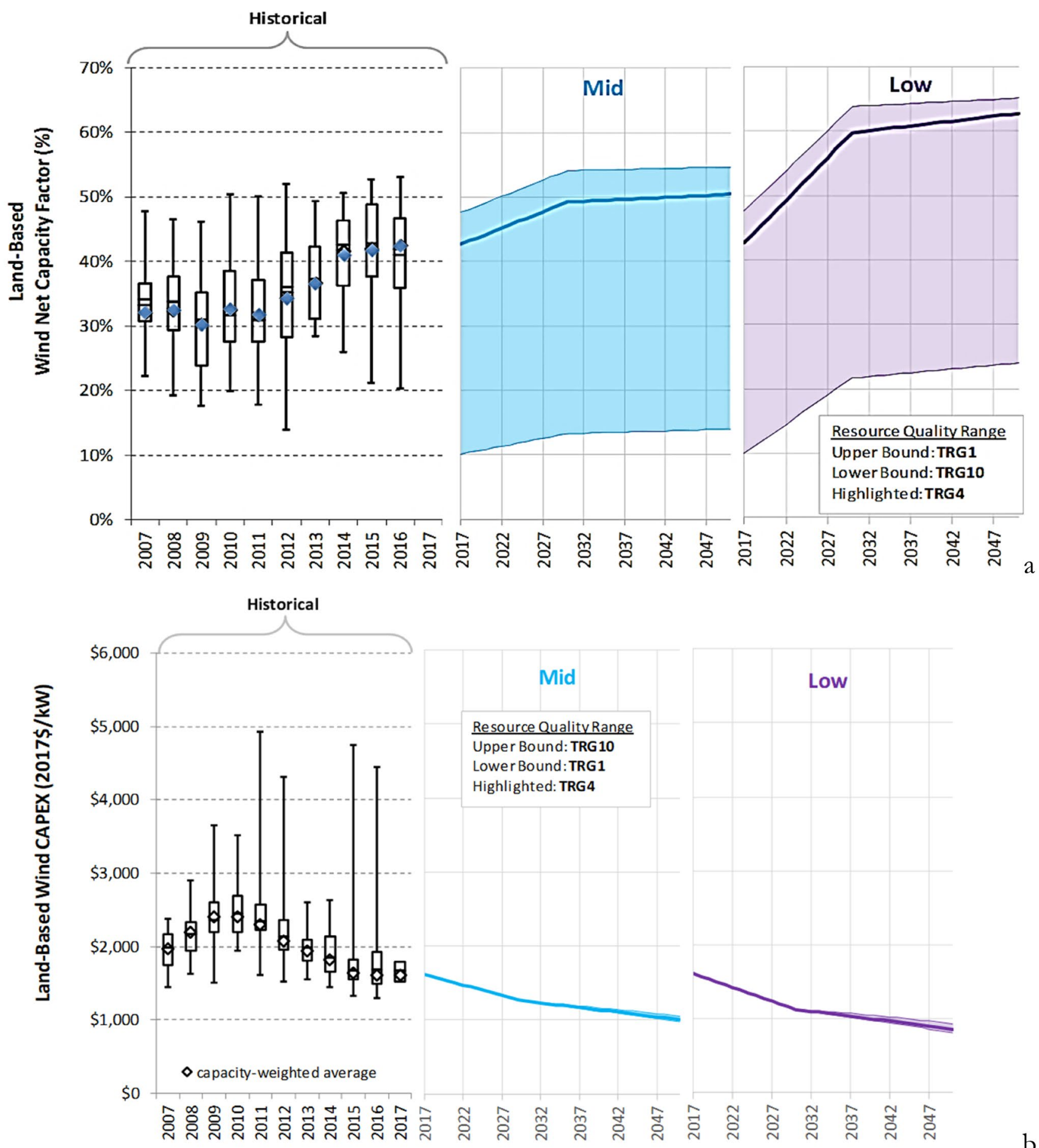

Fig. 1 a annual mean capacity factors of land-based wind energy facilities in the US. Image reproduced modified from [32]. b their CapEx. Image reproduced modified from [33]. Credit National

speeds (TRG 1) or low wind speeds (TRG 10). Future projections are shown for hypothetical Mid and Low technology
Renewable Energy Laboratory. Most of the wind energy facilities in the U.S. are techno-resource group (TRG) 4 and above for wind energy

cost scenarios, translating into average improvements 2017-2029 43-50\% (Mid) or 43-60\% (low). 
The figure also presents the CapEx (capital cost per unit installed power). The LCOE will ultimately depend on CapEX, capacity factor $\varepsilon_{a}$ and operation and maintenance costs $(O \& M)$, nominal power $P$ and number of years of operation $N$, typically 20 years,

$L C O E \sim \frac{\operatorname{CapEx} \cdot P+O \& M \cdot P \cdot N}{\varepsilon_{a} \cdot P \cdot n_{a} \cdot N}$

where CapEx is in $\$$ per kW, O\&M is in $\$$ per kW per year. From Fig. 1, 2011-2017 the CapEx has reduced from about $2,300 \$ \mathrm{US} / \mathrm{kW}$ to $1,600 \$ \mathrm{US} / \mathrm{kW}$ and it is further reducing.

20 years is the typical duration of power purchase agreements (PPA). The design life of a good quality wind turbine is 20 years. Sometimes, the turbines may last for 25 years or even longer, though the maintenance costs increase as they get older.

From this picture, it seems that the mean capacity factor has been dramatically increasing, 2011-2017, it is presently dramatically increasing (the ATB version considered is 2019), and that their variability may be neglected, as no mention is made in the ATB of wind energy variability, that is therefore not a problem. We know otherwise, [26] to [31], that the wind farms of the US, mostly in areas of good resource TRG4 and above, are operating well below the alleged $43 \%$, at about the same $33 \%$ of 2011 , and similarly are doing the wind energy facilities of Australia sharing about same good wind resource. Additionally, [26] to [28], and [31], the variability is significant, especially if high-frequency data are considered [27, 28]. Statistically, the standard deviation of the capacity factor fluctuations about the annual mean of individual facilities is the same order of magnitude of the annual mean, for coefficients of variability about unity. Even when considering the wind energy supply to a very large grid from all the wind energy facilities, the variability of wind energy supply is still dramatic and it requires massive energy storage to avoid back-up fossil fuel plants [27, 28]. The aim of this work is thus to analyze real-world data to verify if the trends for CapEx (capital cost per unit installed power) and the average of the annual mean capacity factors in the NREL ATB 2019 [16] is correct and if it is similarly appropriate to neglect the variability.

Equation (1) may also be used to define capacity factors over shorter time intervals. If monthly values of electricity production $E_{m}$ are available, then $n_{m}$ is the number of hours in the specific month, and $\varepsilon_{m}$ is the capacity factor of every month.

$\varepsilon_{m}=\frac{E_{m}}{P \cdot n_{m}}$

Over 1 year, there are 12 values to consider. If values of electricity production are available every minute, $E_{1 \mathrm{~min}}$ then $\varepsilon_{1 \min }=\frac{E_{1 \min }}{P \cdot(1 / 60)}$

Over 1 year, there are 525,600 values to consider, $(527,040$ in leap years). These two populations permit to assess the low and high-frequency variability of the capacity factor as the standard deviation $\sigma_{m}$ of the $\varepsilon_{m, i} i=1$ to 12 or the standard deviation $\sigma_{1 \min }$ of the $\varepsilon_{1 \text { min, ir }} \mathrm{i}=1$ to 525,600 $(527,040)$.

For the US, data are available at the most a monthly frequency. Monthly mean data are considered for 100 facilities totaling $21.3 \mathrm{GW}$ of total nominal generating power. For Australia, where higher frequency data is available, the total wind energy produced by the 57 different facilities connected to the National Electricity Market (NEM) grid is then considered with a higher frequency sampling rate of $3 \mathrm{~h}$ and $5 \mathrm{~min}$. Electricity production data sampled with 1 -min frequency is nowhere to be found, but it is what is needed to design the energy storage $[26,27,31]$.

The time series of the individual U.S. wind energy facilities will be used to verify the claim of a present average capacity factor of $43 \%$ dramatically increasing. The time series of all the Australian wind energy facilities of the NEM grid will then be used to show the importance of the variability that must be finally factored in wind energy studies. It must be noted that a balanced grid does not require every single wind energy facility to be balanced. However, it is the total wind and solar energy supply to a common grid that must be balanced every minute. The cost of the balance, either by energy storage or by combustion fuels, will have then to be shared between all the wind and solar energy facilities directly proportional to their energy supply, but also inversely proportional to their annual mean capacity factor, and directly proportional to their standard deviation $\sigma_{1 \text { min }}$.

\section{Analysis of a statistical sample of U.S. wind energy facilities}

Here we show as based on real-world data of the 100 latest and largest wind energy facilities in the US, selected in the database of the U.S. Energy Information Administration (U.S. DOE), [34], and here analyzed, Fig. 2a, b, that the annual mean capacity factor $\varepsilon_{\mathrm{a}}$ is not larger in facilities completed more recently.

The average of all the monthly mean results from the different facilities shows the same low-frequency seasonal oscillations about one de-trended line of annual mean capacity factors stable at about $33 \%$ over the last 8 years, Fig. 2a, b. The new facilities added every single year since 2012, have been performing about the same 

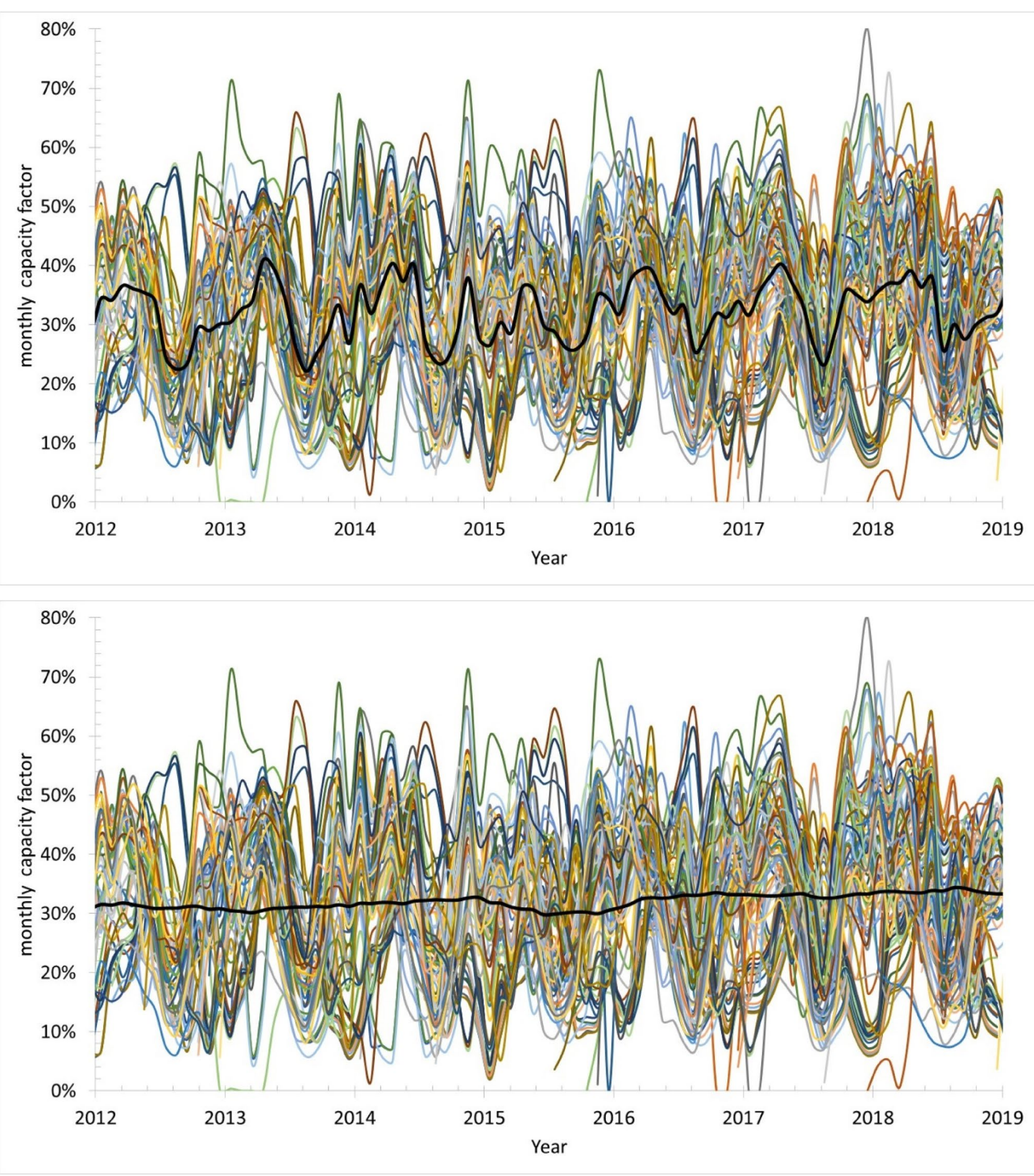

Fig. 2 a and $\mathbf{b}$ monthly mean capacity factors of the 100 latest and largest land-based wind energy facilities in the US, of total capacity 21.3 GW, highlighting in (b) the monthly average of all the facilities, and in c the 12-months-moving-average of the monthly average of all the facilities. Data downloaded from [34]. Credit for data Energy Information Administration (U.S. DOE)

is not the case, there are relevant fluctuations. These fluctuations are evidenced also by the inadequate monthly averaging statistic, which is filtering out the most of the variability. 
The real-world data thus shows how the annual mean capacity factors are fairly stable, and their variability is significant also with a low-frequency statistic, and definitively worth attention. This is not a surprise, as there is no reason to expect an increment of the annual mean capacity factors of wind energy facilities, and it should not be expected a small variability in the wind energy production from the known large variability in the wind energy resource.

Recent years have not been characterized by any significant breakthrough in wind turbines technologies, but only minor changes. The wind energy facilities completed in the different recent years often use the same turbines of previous years' facilities. Hence, it would be a surprise if there could have been an increase in the mean capacity factor from 33 to $43 \%$ over the recent years, as it is shown in Fig. 1, by the completion of other facilities proposing the same technologies.

Our analysis of the 100 latest and largest wind energy facilities in the U.S. shows 12 months moving averages of the average of the monthly mean capacity factors of the individual wind energy facilities that are not increasing. The power of the different facilities ranges from 736 to $80 \mathrm{MW}$, with an average of $213.3 \mathrm{MW}$, for a total installed capacity of $21.3 \mathrm{GW}$. The largest wind energy facilities such as Los Vientos, or Alta Wind, comprise more units treated individually. The average of the annual mean capacity factor is presently about the same as what it has been every year since January 2012. This analysis is an extension and an update of the analysis performed in [26], by using data of more wind energy facilities, and data further expanded up to December 2018, and, in some cases, September 2019.

Over the year 2018, the annual mean capacity factors of the 100 largest and latest wind energy facilities in the U.S. have been characterized by a maximum of $51.13 \%$, a minimum of $13.65 \%$, and an average of $33.33 \%$. The standard deviation of the distribution is $7.50 \%$, i.e. the vast majority of the wind energy facilities perform about the mean of the population. This result is conflicting with the "historical" data to 2016 proposed by the U.S. NREL ATB [16] and presented in Fig. 1, as well as with their forecasted further dramatic growth $2017-2027,43-50 \%$, or $43-60 \%$ following two different scenarios, but it is perfectly consistent with the real-world data proposed by the EIA, U.S. Energy Information Administration (U.S. DOE), Table 6.07.B. Capacity Factors for Utility Scale Generators Primarily Using nonfossil Fuels issue October 2019 [35].

Over the last decade, the annual mean capacity factors of all the wind energy facilities of the U.S. have been marginally growing from the $32.2 \%$ of 2011 to the $34.5 \%$ of 2016 and $34.6 \%$ of 2017 and 2018 . The statistical sample used in this work produces an average of the annual mean capacity factor of $33.33 \%$ for 2018 that is relatively close to the EIA result. Hence, our statistical sample well represents the complete population of wind energy facilities in the US. Opposite, the statistical sample used by NREL suggests an about $43 \%$ average of the annual mean capacity factors for 2014, 2015, and 2016 that is largely more than the true value. Also to note, the statistical sample used by NREL includes the high performing outliers (capacity factors up to 54\%) but it does not include the low performing outliers (no facility performing less than $20 \%$ capacity factor).

If the low-frequency variability is expressed as the ratio of the difference between the monthly mean maximum and minimum capacity factors in the same year, divided by the annual mean capacity factor of the year, this variability has ranged in 2018 among the 100 latest and largest wind energy facilities in the U.S. from a maximum of $176.68 \%$ to a minimum $29.95 \%$ with an average $89.77 \%$. The standard deviation of this latter variability parameter is $31.13 \%$. By considering all the wind energy facilities connected to the same grid, as it is not the case in the US, the monthly mean values have ranged between $39.13 \%$ and $25.68 \%$, for lowfrequency variability of $40.40 \%$.

Having more recent installations of wind turbines placed in more favorable areas that what is done in the European Union (for obvious reasons it is easier to find much larger flat areas of higher and more stable wind speed in the U.S. and Australia than for example Germany), the average of annual mean capacity factors is approaching the mid-30\% in both the U.S. and Australia, that is well above the average of annual mean capacity factors of Germany [36]. Based on real-world electricity production data from the electricity operator, same of the U.S. and Australia in this paper, the average of the monthly mean capacity factors fluctuates seasonally between 10 and $30 \%$, reaching values above $40 \%$ only a few times in the best season (winter). The annual mean capacity factor is stable at slightly below 20\% from the year 2000 to the year 2014 . These about stable conditions are obtained with average ages of turbines increasing, average rotor swept area also increasing (and thus increasing rotor diameter and hub height), average turbine capacity increasing, the specific power of turbine per unit area flat since 2004. The downgrading of capacity factors in Sweden is quantified by [37] in $0.15 \%$ capacity factor loss per year, corresponding to a lifetime energy loss of $6 \%$. Performance decline with age is quantified in a much larger $16 \%$ per decade in [11]. The reduction of wind energy production because of the interactions between the turbines is very well known [38]. The limit of electricity generation from wind, but at the time of a much larger global uptake of wind energy, is also commented in [39]. This is the less relevant present problem of wind energy development. 
Regarding costs, while we do not have the same highquality data as the EIA data for the capacity factor, we may report some costs. Completed 2008-2010 the Roscoe Wind energy facility of power 781.5 MW had a cost above $1 \mathrm{~b}$ \$US. This is about $1280 \$ \mathrm{US} / \mathrm{kW}$. The units I to IX of Alta Wind, totaling $1320 \mathrm{MW}$, and completed 2011-2012, had a cost of $2.875 \mathrm{~b} \$ \mathrm{US}$. This is 2178 WUS/kW. The $496.6 \mathrm{MW}$ Bison Wind Energy Center completed in 2015 has a cost of $0.8 \mathrm{~b}$ \$US. This is about 1611 \$US/kW.

While the message from Fig. 1 is that wind energy is characterized by growing capacity factors and reducing costs, for dramatically reduced LCOE forecasted over 20 years of operation and not delivered, while there is a reliable database that permits to question the trend for the capacity factor, there are only scattered, unverified information about the costs that prevent any statement relative to the CapEx.

\section{Detailed analyses of two U.S. wind energy facilities}

If we consider the example of Alta Wind Energy Center, the largest onshore wind energy project in the world, Fig. 3a, Alta Wind XI and X, completed in 2014, use the same turbines of Alta Wind II to V completed in 2011, and also the same turbines of Alta Wind VI to VIII completed in 2012. During the year 2018, the first completed unit of Alta Wind, I of 2011, has been performing better than any other subsequent Alta Wind unit, II to X, except the much smaller Alta Wind XI. All the Alta Wind facilities have then been performing below the $33.33 \%$ average annual mean capacity factor for 2018 of the 100 facilities surveyed. During the year 2019, the 11 Alta Wind facilities have been working with annual mean capacity factors of $30.37,26.60$, $27.46,19.99,19.34,23.08,23.04,20.54,21.11,30.88$ and $33.13 \%$ respectively. The most of the Alta Wind facilities, 10 of 11 , with the only exclusion of Alta Wind I, use Vestas turbines model V90/3000 of rated power $3 \mathrm{MW}$ and rotor diameter $90 \mathrm{~m}$. The hub height is $80 \mathrm{~m}$ in the Alta Wind installations. These turbines are available on the market since 2002. Their rated wind speed is $16.5 \mathrm{~m} / \mathrm{s}$. Thus, they deliver their rated power only for wind speeds roughly aligned with the rotor axis of $16.5 \mathrm{~m} / \mathrm{s}$ and above, up to the cut-out speed. This is not a condition occurring very often also at $80 \mathrm{~m}$ of height.

Present average of annual mean capacity factors for land wind energy facilities in the U.S. have not increased from about $33 \%$ in 2012 to about $43 \%$ in 2017, as it is shown in Fig. 1, and it is unreasonable to expect their further increase to about $50 \%$, or even to about $60 \%$, by 2027 in just 10 years, as also shown in Fig. 1. A more accurate statistic is needed, also accounting for the variability, and projections for the future should be made more grounded. Our sample population statistic made up of the 100 largest and latest facilities, or the summary results by EIA for all the wind energy facilities of the US, [34] show a different story.

Wind energy research is characterized by excessive optimism. By using popular codes such as the National Renewable Energy Laboratory (NREL) System Advisor Model (SAM), [40, 41], the overrated representation of the wind energy resource produces dramatically overrated performances of wind energy facilities. For example, by using the Southwestern TX flat lands NREL AWS Truepower representative wind energy resource for the Los Vientos, TX location, in the SAM model every Vestas V110/2000 turbine placed at $100 \mathrm{~m}$ hub height is computed to work positioned in a wind energy facility with an annual mean capacity factor of $59.2 \%$. Los Vientos III, IV, and $V$ have these turbines working at very different annual mean capacity factors, in 2018 39.92, 41.54, and 38.39\%. If the turbine is changed to Siemens SWT 108/2.3 placed at the same height, the annual mean capacity factor of a facility built with these turbines is $57.7 \%$. Los Vientos $1 \mathrm{~A}$ has these turbines working at very different annual mean capacity factor, in $201835.77 \%$.

The model result for the electricity production of the wind energy facility modeled in SAM is extremely simple. At every time $t_{i,}$, the power of electricity production is very close to the value from the power curve for the prescribed wind speed $v_{i}, P\left(v_{i}\right)$, multiplied by the number of turbines in the facility $n$. If $m$ is the last observation and 1 the first, the energy produced over the time interval $t_{m}-t_{1}$ is, therefore:

$E_{1, m}=n \cdot \sum_{i=1}^{m} P\left(v_{i}\right) \cdot \Delta t_{i+1 / 2, i-1 / 2}$

where $\Delta t_{i+1 / 2, i-1 / 2 / 2}$ is the time interval where electricity is produced at this average power. Every other effect, including the density variation following the seasonal temperature variation, is practically neglected. Much better results were obtained by using in [26] the Mathematica function to source wind speed and temperatures close to the location of the wind energy facility, then extrapolating the values of wind speed at hub height from a power-law, and introducing a correction for density:

$E_{1, m}=n \cdot \sum_{i=1}^{m}\left(\frac{T_{0} \cdot p_{i}}{T_{i} \cdot p_{0}}\right) \cdot P\left(v_{i}\right) \cdot \Delta t_{i+1 / 2, i-1 / 2}$

where $T_{0}$ and $p_{0}$ are the reference temperature and pressure for the measurement of the power curve and $T_{i}$ and $p_{i}$ are the temperature and pressure at the time $t_{i}$. The power curve correction is consistent with the IEC 

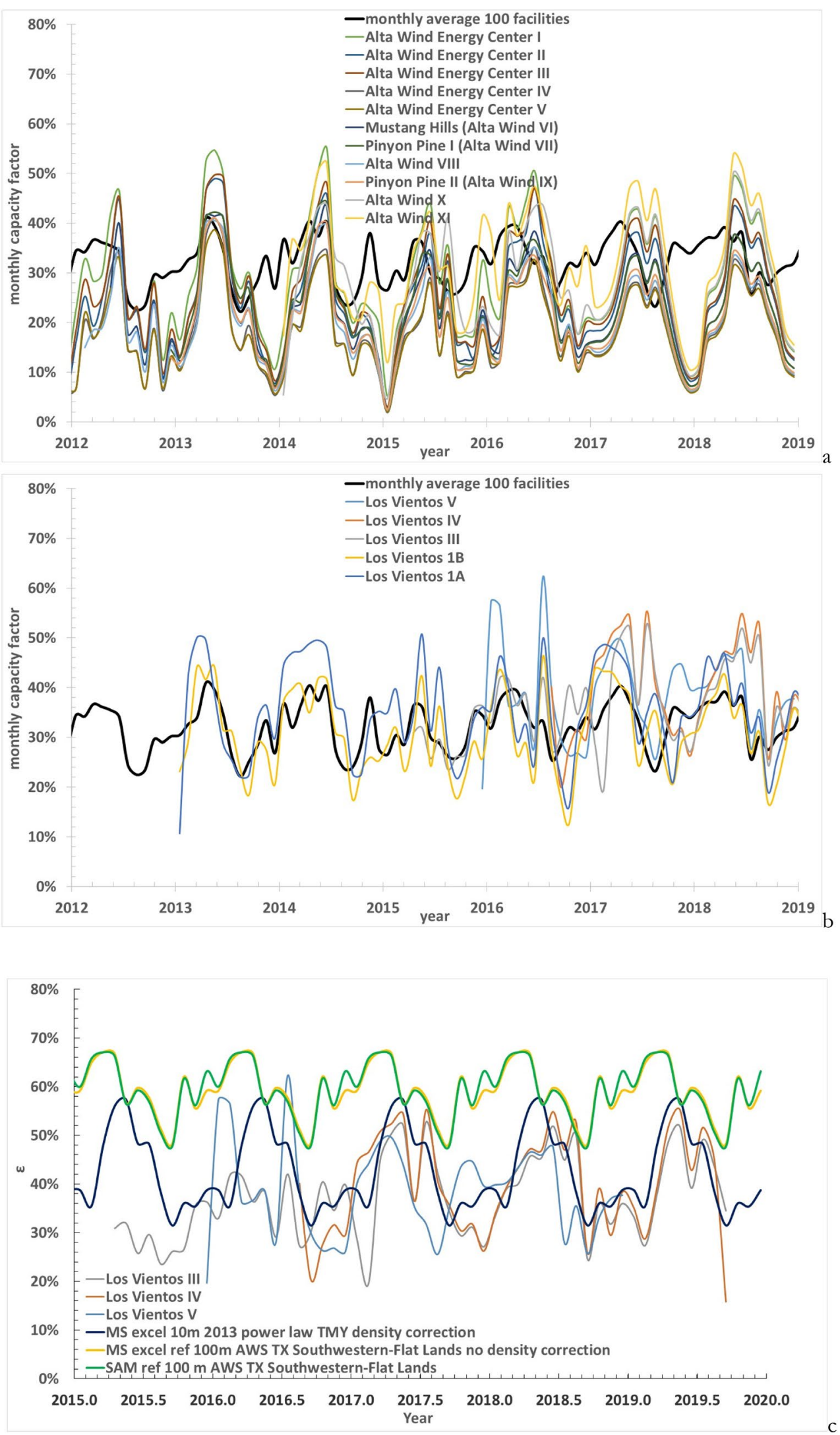
4 Fig. 3 a and b monthly mean capacity factors of the Alta Wind energy facilities I to XI and Los Vientos 1A, 1B, and III to V. Data downloaded from [34]. Credit for data Energy Information Administration (U.S. DOE). c monthly mean capacity factors for a wind energy facility using Vestas V110/2000 turbines of hub height $100 \mathrm{~m}$, from SAM with the reference $100 \mathrm{~m}$ AWS wind resource for the South Western Texas flatlands, computed by MS Excel following Eq. (2) with same wind resource, or computed by MS Excel following Eq. (3) using the 2013 measurements of wind speed at $10 \mathrm{~m}$ and a power law of exponent 0.245 , plus the density correction from pressure and temperature of the typical year. The experimental results of Los Vientos III, IV, and V featuring the same turbines are also shown over all the years of operation

61400-12 standard for the measurement of wind turbine power curves. The power curve measured at one specific air density is corrected by the ratio to the standard air density of $1.225 \mathrm{~kg} / \mathrm{m}^{3}$. This is the International Standard Atmosphere (ISA) density of air at sea level 1.01325 bar of pressure and $288.16 \mathrm{~K}$. The much better accuracy of [26] is the result in a greater extent of the much more reasonable, smaller wind speed at hub height, and in a minor extent of the density correction through the temperature that better explains the observed seasonal variability.

From the power curve $P(v)$, and the rotor diameter $D$, the efficiency of the wind energy collection trough a turbine rotor is

$\eta=\frac{P}{1 / 2 \cdot \rho \cdot\left(1 / 4 \cdot \pi \cdot D^{2}\right) \cdot v^{3}}$

where $\rho$ is the air density and $\eta$ is the total turbine efficiency, including aerodynamics, transmission, and generation losses. $\eta(v)$ always has a peak at a wind speed below the rated speed, preferably the most likely wind speed. Attention to $\eta$ is however misleading, as the wind resource has no price, and more relevant is to ensure than the power of electricity production is the closest possible to the rated power.

As shown in Fig. 3b, in the real world, the turbines Vestas V110/2000, 2.0 MW, $110 \mathrm{~m}$ rotor diameter, $100 \mathrm{~m}$ hub height, of Los Vientos III, IV, and V have been working over the year 2018 with capacity factors of 38.39, 41.54 and $39.92 \%$, while the turbines Siemens SWT 108/2.3, 2.3 MW, $108 \mathrm{~m}$ rotor diameter, $100 \mathrm{~m}$ hub height, of Los Vientos $1 \mathrm{~A}$, have been working over the year 2018 with capacity factors of $35.77 \%$.

The difference between computations with SAM and the experiments is huge, as the annual mean, as well as the monthly mean. The SAM result originates mostly from the overrated wind energy resource, and it is also affected by the neglected density effects but less. The simple model of [26] using the Mathematica functions for wind speed and air temperature, a power log law to bridge the measurements at near ground level to the hub height, and the power curve of the turbine, produces much more realistic results. However, the NREL AWS Truepower representative wind energy resource and SAM are used routinely to assess wind energy potentials, clearly overrating them.

Figure $3 \mathrm{c}$ presents the monthly mean capacity factors for a wind energy facility using Vestas V1 10/2000 turbines of hub height $100 \mathrm{~m}$. The computational results are (1) from SAM with the reference $100 \mathrm{~m}$ AWS wind resource for the South Western Texas flatlands, (2) computed by MS Excel following Eq. (1) with same wind resource, or (3) computed by MS Excel following Eq. (2) using the 2013 measurements of wind speed at $10 \mathrm{~m}$ and a power law of exponent 0.245 , plus the density correction from pressure and temperature of the typical year. The experimental results of Los Vientos III, IV, and V featuring the same turbines are also shown over all the years of operation. The inter-annual variability is significant, as well as the variability between facilities. The average of the annual mean capacity factors of Los Vientos III, IV, and V 2015-2018 is $39 \%$. The AWS Truepower wind resource for the South Western Texas flatlands $100 \mathrm{~m}$ height suggests an annual mean capacity factor of 59\%. The 2013 measured wind speed at $10 \mathrm{~m}$ height, a power-law extrapolation to $100 \mathrm{~m}$ of this speed, and correction for density variation following the typical year pressure and temperature return a much more reasonable annual capacity factor of $42 \%$. The standard deviation of the capacity factors computed every hour during this latter simulation is $39 \%$, for a coefficient of variability approaching unity.

What would be interesting is to have the measured wind speed (and direction) approaching every turbine in the wind farm, plus reference pressure and temperature, plus energy produced by every turbine, sampled with high frequency, to properly validate the models for both resource and wind energy facility.

It is an unfortunate circumstance that models are becoming less, rather than more accurate, and validation exercises are generally omitted before applying techniques to forecast performances of future wind (and other renewable) energy facilities. There is a clear tendency to overrate the virtual world performances of renewable energy facilities, and then omit to consider the real-world results.

Worth to note in Fig. 1d, e, is also the variability in between wind energy facilities almost co-located for what concerns the wind energy resource, even with same turbines, that is evident especially in Los Vientos, with performance curves intersecting each other, but it is also relevant in Alta Wind, with performance curves systematically shifted towards higher or lower capacity factors.

The Vestas turbines model V110/2000 of rated power $2 \mathrm{MW}$, rotor diameter $110 \mathrm{~m}$ and hub height $100 \mathrm{~m}$ in the Los Vientos installations have a rated wind speed of 
$12 \mathrm{~m} / \mathrm{s}$. The Vesta turbines V90/3000 of rated power $3 \mathrm{MW}$, rotor diameter $90 \mathrm{~m}$, and hub height $80 \mathrm{~m}$ in the Alta Wind installations have a rated wind speed of $16.5 \mathrm{~m} / \mathrm{s}$. The main reason why Los Vientos III, IV, and V have much better annual mean capacity factors than the Alta Wind II to $\mathrm{XI}$, apart from the resource, and the hub height, is mostly the much lower rated-speed. The rated speed is much larger than the most likely wind speed in both locations. But because the difference is larger in Alta Wind, the turbines of Alta Wind more often operate below the rated power than the turbines of Los Vientos III, IV, and V. Obviously, one V110/2000 installed with hub height $100 \mathrm{~m}$ has a much larger cost per unit specific power than a V90/3000 installed with hub height $80 \mathrm{~m}$. The attention to the CapEx (capital cost per unit installed power) is therefore once more misleading for the cost of electricity production.

\section{Analysis of the wind energy supply to the Australian NEM grid}

Capacity factors of wind energy facilities vary and this must be factored. A measure of variability is essential to energy storage design [27]. With a high-frequency sampling every $5 \mathrm{~min}$, still not high enough, the 55 wind energy facilities of the Australian National Electricity Market grid, totaling a capacity of $6.7 \mathrm{GW}$, work with an average of the annual mean capacity factors of about 33-35\%, and high frequency (5 min sampling) standard deviations about 30\% [28]. The average of the annual mean capacity factors hasn't changed too much also in Australia, as it was the same 10 years ago $[29,30]$. The addition of significant new capacity every year at an increasing rate is not associated with any improvement of the grid average.

As high-frequency data is unavailable in the US, Fig. 4a, $b$ present the capacity factors of all the land wind energy facilities connected to the Australian National Electricity market grid, and their average, in a sample month and a sample day. These capacity factors are computed every $3 \mathrm{~h}$ for the sample monthly graph, October 2019, or every $5 \mathrm{~min}$, for the sample daily graph, October 23,2019 . On October 23, 2019, the wind energy supply occurred at below $3 \%$ capacity factor grid average over most of the day. In October 2019, grid average capacity factors oscillated between $3 \%$ and $60 \%$. The horizontal lines well below $100 \%$ capacity factor for few facilities originate from the fact that few facilities have been registered for their full capacity while still in construction.

This result shows the relevance of energy storage for wind and solar only grid $[27,28]$, that is impossible without energy storage (the low wind conditions are often correlated also over large areas, and these conditions may also occur after sunset when they solar energy is unavailable).
With higher sampling frequency, the fluctuations in the capacity factors of individual wind energy facilities, as well as of the grid average, increase. Thus, with a sampling every minute or less, the variability may be larger.

\section{Conclusions}

While turbine technologies have not improved that much over the last 8 years, there may have been some increments in rotor diameters that may have translated in slightly higher capacity factors, but mostly because of the slightly higher hub height. However, with larger turbines' rotor diameters, the land demand has also increased, as the relative positioning of the wind turbines for good operation is based on their relative distance expressed in rotor diameters. Hence, generally, the increased packaging has reduced most of the benefits of the higher hub height. Furthermore, as soon as the best locations for wind energy have been saturated, the novel installations are being developed in less favorable areas, in terms of orography and wind energy resource, and this further reduces the achievable benefits. Finally, the focus on cost reduction, targeting the CapEx (capital expenditure per unit nominal installed capacity) has often favored the use of less expensive wind turbines, often producing the rated capacity at a higher speed, with smaller, rather than larger, rotors, and placed at lower, rather than higher, hub heights, and being packed at reduced distances, in less favorable terrains with less favorable wind energy resource, for sub-standard, rather than improved performances.

Based on the above results, it must be concluded that there is no sign of improvements in the average of the annual mean capacity factor of the wind energy facilities in the US. Additionally, there are fluctuations about this average that are worth consideration, as the variability emerges also with an inadequate low-frequency monthly statistic (grid stability requires data with a frequency every minute or less). Also worth mentioning is the difference in performances between different wind energy facilities, which are also almost co-located (see Los Vientos or Alta Wind for example, [26], and Fig. 1d, e, f), in both the annual mean and the proposed fluctuation parameter.

While the annual mean capacity factor is a measure of the nominal capacity needed to supply a given average power to the grid, a variability parameter, such as the standard deviation, better if high frequency, computed with data collected every minute or less, is a necessary measure of the energy storage needed to support a stable supply that is matching the demand. Both parameters are important to properly assess the costs of wind energy supply, and they need to be assessed with accuracy. 


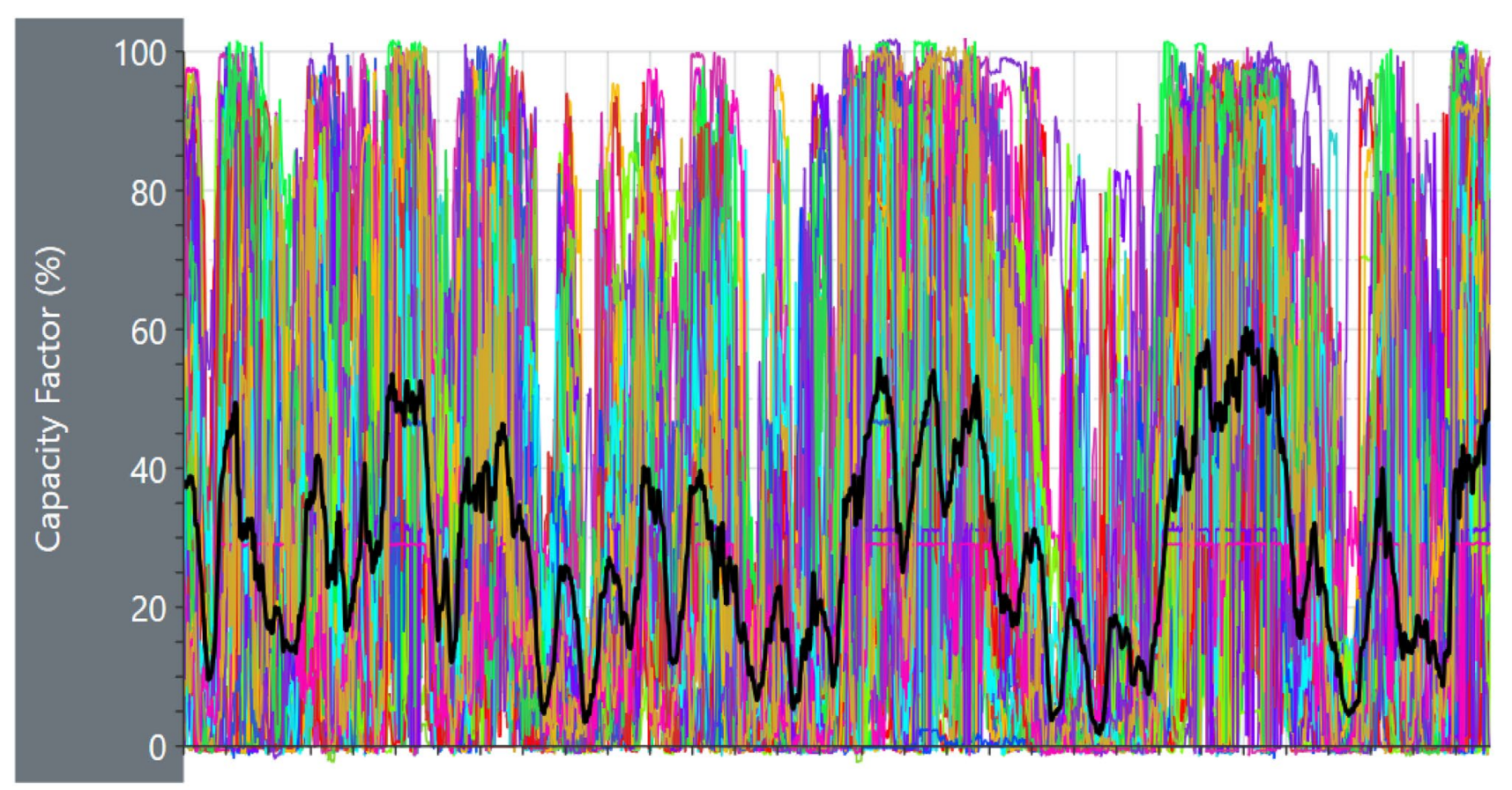

\section{$\begin{array}{llllllllllllllll}01 & 03 & 05 & 07 & 09 & 11 & 13 & 15 & 17 & 19 & 21 & 23 & 25 & 27 & 29 & 31 \\ \mathrm{a}\end{array}$}

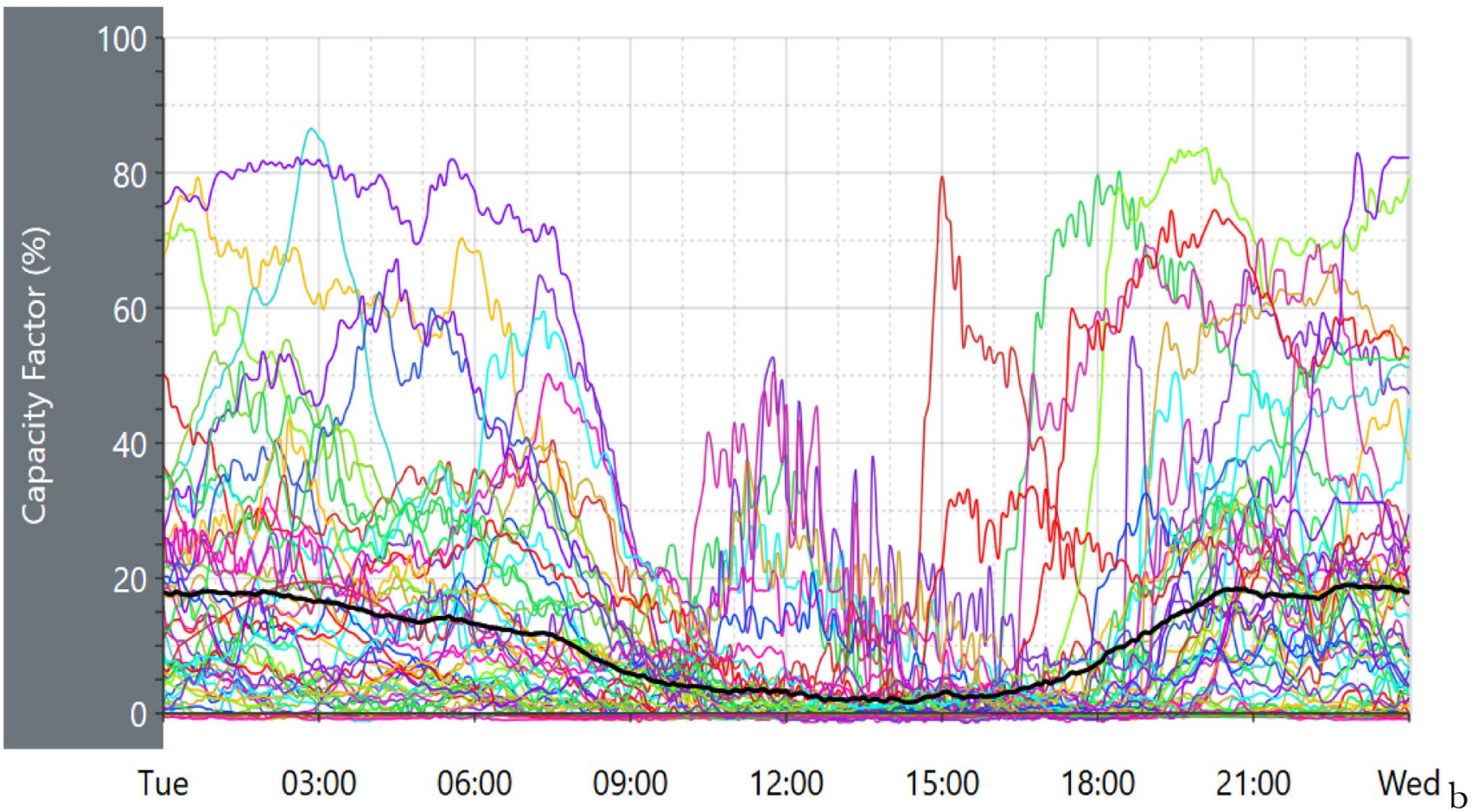

Fig. 4 a and $\mathbf{b}$ Capacity factors of all the land wind energy facilities connected to the Australian National Electricity market grid, totaling $6.7 \mathrm{GW}$ of installed capacity, and their average, computed every

Strong uptake of renewable energy may only follow rewarding the designs of wind energy facilities that provide higher annual mean capacity factors, and smaller variability parameters, and not simply the cost per unit
$3 \mathrm{~h}$ over one sample month (October 2019) and 5 min over one sample day (October 23, 2019). Images reproduced modified from [42]. Credit Andrew Miskelly (Anero.id)

nominal installed capacity. To match a grid demand, the total supply by wind and solar will have definitively to be stabilized by the energy storage. More research and development for energy storage is the key to the further 
expansion of wind and solar energy, both suffering of intermittency and unpredictability.

The data of 100 latest and largest land wind energy facilities in the US, totaling $21.3 \mathrm{GW}$ of installed capacity, and the 54 land wind energy facilities of the Australian National Electricity Market grid, totaling $6.7 \mathrm{GW}$ of installed capacity, evidence that (1) the average annual mean capacity factors are about $33-35 \%$, and they are not improving in recent years; (2) there are large oscillations about these values, already clear with the inadequate monthly statistic, and dramatic with the $3 \mathrm{~h}$ or 5 min statistic. (3) without energy storage, a grid wind and solar only is practically impossible. The need for energy storage should be acknowledged the sooner the better.

The conclusion of this work is extremely clear and relevant. Expectations of reduction of costs and increments of capacity factors, despite popular in the mainstream media, are unsupported by data and by logic. Data has been presented, also explaining that about same technology turbines, located on less favorable land for wind and orography, at about same or only marginally larger hub height, but subjected to increased packaging (good places for wind farms are being quickly saturated) cannot work better than prior installations. Additionally, as the grid must be balanced, increasing the wind capacity without developing energy storage may result in even larger curtailment losses, i.e. a further reduced wind energy supply to a grid not accepting any further supply. Thus, further research and development are urgently needed to (1) develop better turbines and install them in less favorable environments and (2) develop the energy storage.

Acknowledgements The authors received no funding and have no conflict of interest to declare.

\section{Compliance with ethical standards}

Conflict of interest The author(s) declare that they have no competing interests.

\section{References}

1. Boyle G (ed) (2004) Renewable energy. Oxford University Press, Oxford, p 456 ISBN-10: 0199261784. ISBN-13: $\mathbf{9 7 8 0 1 9 9 2 6 1 7 8 9}$

2. Manwell JF, McGowan JG, Rogers AL (2010) Wind energy explained: theory, design, and application. Wiley, Hoboken

3. Palutikof JP, Kelly PM, Davies TD, Halliday JA (1987) Impacts of spatial and temporal windspeed variability on wind energy output. J Clim Appl Meteorol 26(9):1124-1133

4. Pryor SC, Barthelmie RJ, Schoof JT (2006) Inter-annual variability of wind indices across Europe. Wind Energy Int J Progress Appl Wind Power Conv Technol 9(1-2):27-38
5. Junginger $M$, Hittinger $E$, Williams $E$, Wiser R (2020) Onshore wind energy. In: Junginger M, Louwen A (eds) Technological learning in the transition to a low-carbon energy system. Academic Press, pp 87-102

6. Milborrow D (2020) Wind energy development. In: Sayigh A, Milborrow D (eds) The age of wind energy. Springer, Cham, pp 3-22

7. Dalabeeh ASK (2017) Techno-economic analysis of wind power generation for selected locations in Jordan. Renew Energy 101:1369-1378

8. Ayodele TR, Jimoh AA, Munda JL, Agee JT (2012) Wind distribution and capacity factor estimation for wind turbines in the coastal region of South Africa. Energy Convers Manag 64:614-625

9. Chang TP, Liu FJ, Ko HH, Cheng SP, Sun LC, Kuo SC (2014) Comparative analysis on power curve models of wind turbine generator in estimating capacity factor. Energy 73:88-95

10. Dvorak MJ, Archer CL, Jacobson MZ (2010) California offshore wind energy potential. Renew Energy 35(6):1244-1254

11. Staffell I, Green R (2014) How does wind farm performance decline with age? Renew Energy 66:775-786

12. Aldersey-Williams J, Broadbent ID, Strachan PA (2020) Analysis of United Kingdom offshore wind farm performance using public data: improving the evidence base for policymaking. Util Policy 62:100985

13. Miller LM, Keith DW (2018) Observation-based solar and wind power capacity factors and power densities. Environ Res Lett 13(10):104008

14. Miller LM, Keith DW (2019) Addendum: observation-based solar and wind power capacity factors and power densities (2018 Environ Res Lett 13 104008). Environ Res Lett 14(7):079401

15. Diyoke C (2019) A new approximate capacity factor method for matching wind turbines to a site: case study of Humber region, UK. Int J Energy Environ Eng 10(4):451-462

16. U.S. National Renewable Energy Laboratory (2019) Annual technology data base. www.atb.nrel.gov/electricity/2019/index .html?t=lw. Accessed 6 Mar 2020

17. Tegen S, Lantz E, Mai T, Heimiller D, Hand M, Ibanez E (2016) An initial evaluation of siting considerations on current and future wind deployment (No. NREL/TP-5000-61750). National Renewable Energy Lab.(NREL), Golden, CO (United States)

18. Mai T, Lantz E, Ho J, Stehly T, Heimiller D (2016) Outlooks for wind power in the united states: drivers and trends under a 2016 policy environment (No. NREL/TP-6A20-67058). National Renewable Energy Lab.(NREL), Golden, CO (United States)

19. Lantz E, Mai T, Wiser RH, Krishnan V (2016) Long-term implications of sustained wind power growth in the United States: direct electric system impacts and costs. Appl Energy 179:832-846

20. Wiser R, Bolinger M (2016) 2015 wind technologies market report. www.emp.lbl.gov/sites/default/files/2015-windtechre port.final_.pdf

21. Moné $C$, Hand M, Bolinger M, Rand J, Heimiller D, Ho J (2016) 2015 cost of wind energy review. www.nrel.gov/docs/fy17o sti/66861.pdf

22. Lopez A, Roberts B, Heimiller D, Blair N, Porro G (2012) U.S. renewable energy technical potentials: a GIS-based analysis. www.nrel.gov/docs/fy12osti/51946.pdf

23. Wiser R, Jenni K, Seel J, Baker E, Hand M, Lantz E, Smith A (2016) Forecasting wind energy costs and cost drivers: the views of the world's leading experts. www.emp.lbl.gov/publications/forec asting-wind-energy-costs-and

24. Wiser R, Bolinger M, Barbose G, Darghouth N, Hoen B, Mills A, Weaver S, Porter K, Buckley M, Oteri F, Tegen S (2014) 2013 wind technologies market report. www.energy.gov/sites/prod/files 
/2014/08/f18/2013\%20Wind\%20Technologies\%20Market\%20 Report_1.pdf

25. Mayes F (2015) Wind generation seasonal patterns vary across the United States. www.eia.gov/todayinenergy/detai I.php?id=20112

26. Boretti A, Castelletto S (2019) Low-frequency wind energy variability in the continental contiguous United States. Energies 13:144. https://doi.org/10.3390/en13010144

27. Boretti A (2019) Energy storage needs for an Australian National Electricity Market grid without combustion fuels. Energy Storage. https://doi.org/10.1002/est2.92

28. Boretti A (2019) High-frequency standard deviation of the capacity factor of renewable energy facilities-part 2: wind. Energy Storage 1(6):e100

29. Miskelly A, Quirk T (2009) Wind farming in Southeast Australia. Energy Environ 21(8):1249-1255

30. Miskelly P (2009) Wind farms in eastern Australia-recent lessons. Energy Environ 23(8):1233-1260

31. Boretti A, Castelletto S (2020) Cost of wind energy generation should include energy storage allowance. Sci Rep 10:2978. https ://doi.org/10.1038/s41598-020-59936-x

32. U.S. National Renewable Energy Laboratory (2019 Annual technology data base. Onshore wind capacity factor. www.atb.nrel. gov/electricity/2019/images/onshore/chart-onshore-capacityfactor-2019.png. Accessed 6 Mar 2020

33. U.S. National Renewable Energy Laboratory (2019) Annual technology data base. Onshore wind Capex. www.atb.nrel.gov/elect ricity/2019/images/onshore/chart-onshore-capex-RD-2019. png. Accessed 6 Mar 2020

34. U.S. Energy Information Administration (EIA) (2020) Electricity data browser. www.eia.gov/electricity/data/browser. Accessed 6 Mar 2020
35. U.S. Energy Information Administration (EIA) (2020) EPM Table. Browser. www.eia.gov/electricity/monthly/epm_table_graph er.php?t=epmt_6_07_b. Accessed 6 Mar 2020

36. Germer S, Kleidon A (2019) Have wind turbines in Germany generated electricity as would be expected from the prevailing wind conditions in 2000-2014? PLoS ONE 14(2):e0211028

37. Olauson J, Edström P, Rydén J (2017) Wind turbine performance decline in Sweden. Wind Energy 20(12):2049-2053

38. Beyer HG, Pahlke T, Schmidt W, Waldl HP, de Witt U (1994) Wake effects in a linear wind farm. J Wind Eng Ind Aerodyn 51(3):303-318

39. Miller LM, Kleidon A (2016) Wind speed reductions by largescale wind turbine deployments lower turbine efficiencies and set low generation limits. Proc Natl Acad Sci 113:13570-13575

40. U.S. National Renewable Energy Laboratory (2019) System advisory model (SAM), Wind. www.sam.nrel.gov/wind.html. Accessed 6 Mar 2020

41. Freeman, J.; Gilman, P.; Jorgenson, J.; Ferguson, T., 2014. Reference Manual for the System Advisor Model's Wind Performance Model. National Renewable Energy Laboratory, NREL/ TP-6A20-60570

42. Miskelly $A$ (2020) Anero.id, wind energy. www.anero.id/energy/ wind-energy. Accessed 6 Mar 2020

Publisher's Note Springer Nature remains neutral with regard to jurisdictional claims in published maps and institutional affiliations. 